\title{
Emerging voice: Exploring the process of teacher- student dialogic interaction in mobile instant messaging (MIM) to construct voice in argumentative writing
}

\author{
Yeni Latipah* and Wawan Gunawan \\ Department of English Education, Faculty of Language and Literature Education, \\ Universitas Pendidikan Indonesia, Jl. Dr. Setiabudhi No. 229, Bandung, West Java, Indonesia
}

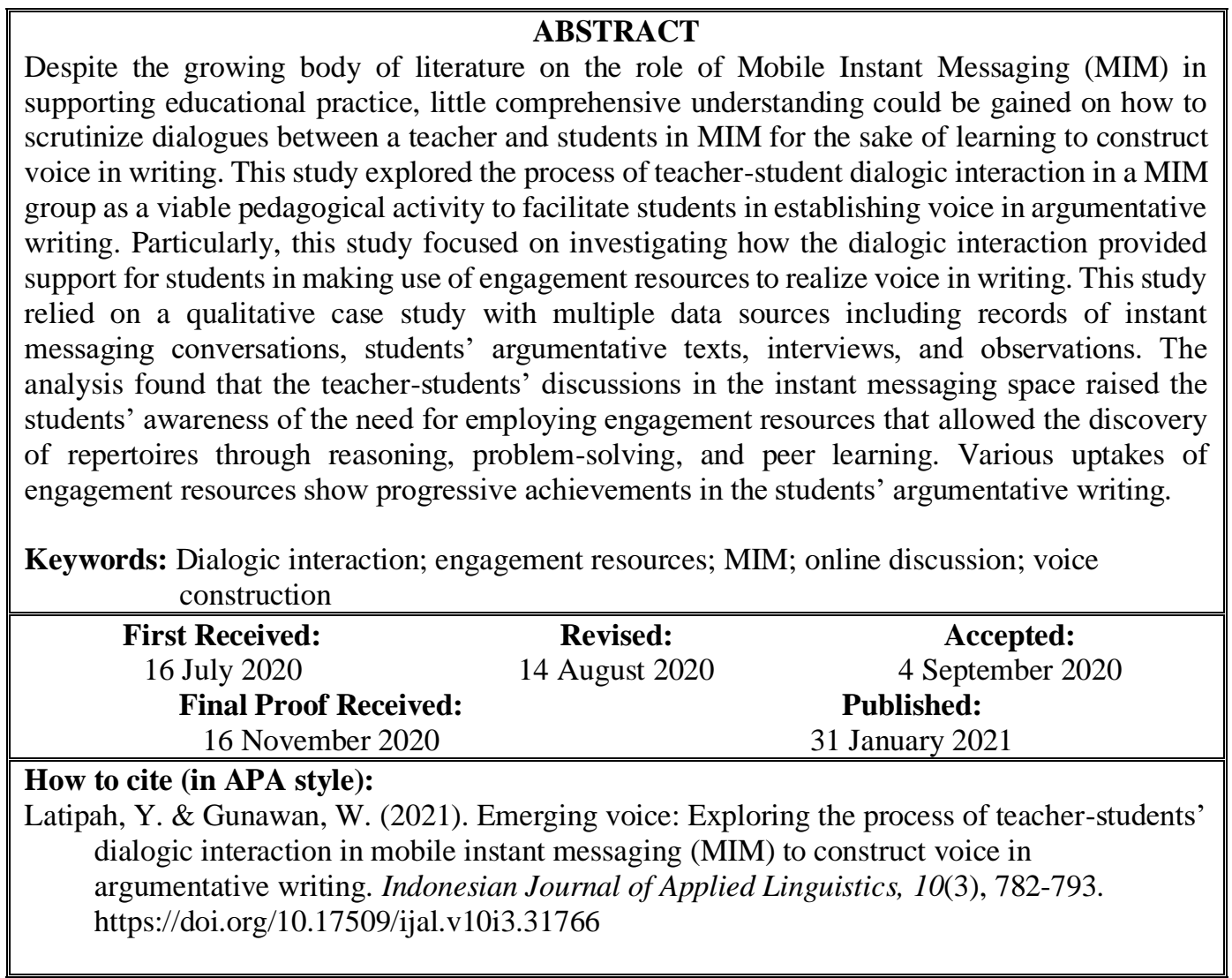

\section{INTRODUCTION}

The incredibly massive use of mobile instant messaging (MIM) has been evaluated by many researchers as a potential tool to support language learning (Andújar-vaca \& Cruz-Martínez, 2017; Andujar, 2016; So, 2016; Tang \& Hew, 2017; Winet, 2016). MIM is an asynchronous and synchronous communication device that utilizes wireless networks and handheld tools (Andujar, 2016). MIM has allowed students and teachers to build communication easily by the use of, for example, WhatsApp, Telegram, WeChat, Viber (Sivabalan \& Ali, 2019). The genuine potential of MIM as an educational tool is due to its ubiquitous nature and special features (So, 2016) such as in creating a group, managing group members, maintaining relatively high privacy levels, and enabling sharing and collaboration (Tang \& Hew, 2017). These rigorous use of MIM could leverage the effectiveness of mobile learning (Primmer et al., 2018) because it provides a supportive and effective environment to foster numerous activities of teaching and learning (So, 2016).

One of the specific ways in which MIM is used in education is for the function of teacher-student dialogic interaction (Tang \& Hew, 2017). 
Maintaining dialogue among teachers and students is always a crucial part of any educational processes (Woods \& Bliss, 2016). Especially in distance education, involving students in virtual dialogic activities is essentially important because teachers could identify crucial information about their pupils (Azevedo et al., 2011). Students could also interact and collaborate with their teachers and peers at a distance to share and reflect on their knowledge (Alebaikana \& Troudia, 2010). These interactive distance activities have become part of evolving academic literacy practices (Hewings, 2012), which is feasible to support the process of transferring, sharing and co-construction of new knowledge (Tan, 2016), including language learning.

However, although there is a considerable amount of research regarding the use of MIM in supporting educational practice, the issue of how to utilize the dialogue between teacher and students in MIM to support students' meaning-making process remains inconclusive. Previous studies on MIM are mostly experimental, examining the role of MIM to develop students' oral skill (Andújar-vaca \& CruzMartínez, 2017), writing skill (Andujar, 2016; Awada, 2016; Minalla, 2018), learning achievement (So, 2016), and language proficiency (Hamad, 2017; Ta'amneh, 2017). Such of these experimental studies somehow reveal the powerful benefits of MIM as a pedagogical tool, yet they merely provided statistical data without grounding the analysis in the nature of the instant messaging conversation.

This study, therefore, attempted to add to the currently limited investigation of how teacherstudent interaction in a MIM group could be a viable pedagogical activity in fostering students' awareness of voice as a vital element in argumentative writing. Through employing the framework of dialogic approach (Alexander, 2008; Gillies, 2015; Wingate, 2019) and engagement analysis (Martin \& White, 2005), this present study explored how the frameworks can serve as an heuristic approach to highlighting the features of dialogic interaction between teachers and students in MIM as well as the establishment of key rhetorical goals of voice in students' argumentative texts.

\section{The potential of MIM in supporting Second Language (L2) writing}

For the last two decades, MIM has been a social phenomenon that influences people's communication. For educational purposes, MIM could offer a virtual learning environment (VLE), enabling the process of delivering learning resources and bridging communication among teachers and learners. Such virtual learning interaction could facilitate the transfer, sharing, and co-construction of knowledge as well as the sharing of experiences among teachers and students (Tan, 2016). More importantly, Pimmer et al. (2016) stated that MIM could facilitate more distributed and frequent practice since it can reach the learners in and across classrooms.

Previous educational research on MIM mostly revealed that utilizing instant messaging as teaching tools has significantly improved the learning process and outcomes (Sivalban \& Ali, 2019), including the process of learning L2 writing. For instance, Andujar (2016) conducted an experimental study investigating the benefits of Mobile Instant Messaging (MIM) towards grammatical, lexical, and mechanical accuracy as well as syntactic complexity in second-language students' writing. He found that there were significant differences between the control and experimental groups in terms of accuracy. He then came up with a conclusion that WhatsApp constituted a powerful educational tool to encourage dialogic interaction among participants. This finding further strengthens the idea that MIM is highly favorable to be integrated into writing instruction.

\section{Voice in argumentative writing}

Voice has been confirmed as a significant component and a big predictor of argumentative writing quality (Cheung et al., 2018; Yoon, 2017; Zhao, 2019; Zhao \& Liosa, 2008; Zhang \& Zhan, 2019). It is broadly defined as "individual knowledge claims or authorial presence and opinion on propositional information" (Guinda \& Hyland, 2012, p. 4). Lee and Deakin (2016) believe that constructing voice in argumentative writing could possibly bolster a writer's affective position toward the content and the readers, leading to the establishment of the writerreader rapport. Furthermore, through selecting appropriate linguistic resources in establishing voice in argumentative writing, writers would be able to acknowledge the source texts, show how evidence from source texts relates to their claims, manage multiple perspectives (Pessoa et al., 2019), and ultimately construct an argumentative text that is regarded as effectively persuasive because it addresses the interlocutors' discursive goals (van Eemeren, 2018). Therefore, providing instruction by explicitly stressing the role of voice in argumentative writing is central for students to make them aware of how to convey their personal attitudes and appropriately connect with their readers (Guinda \& Hyland, 2012).

\section{Constructing students' voice through a dialogic approach}

Dressen-Hammouda (2014) argues that voice is an individual's response to social interaction. In other words, voice is co-constructed or inherently involves the role of others to produce it in a text. The establishment of voice could be achieved through the process of dialectic relationship with the others' content knowledge (Zacharias, 2018) that are generally situated in a particular discourse of writing (Hyland, 2012). This understanding of voice as socioverbal interaction which derives from Bakhtinian 
dialogism (1981) reflects the importance of exploring patterns of teacher-student communication (Skidmore \& Murakami, 2016), to examine the role of such interaction to help students establish voice in the text.

Toward the case, teacher-students interaction in the atmosphere of a dialogic approach is considered potential to develop students' voice. The dialogic approach to teaching was mainly popularized by Alexander (2008) and disseminated by a number of researchers (Hammond, 2016; Jesson \& Rosedele, 2016; Skidmore \& Murakami, 2016; Teo, 2016; Van Der Heide et al., 2016). It capitalizes on the power of talk to foster students' thinking, learning, and problem solving (Alexander, 2008). Reina and Clark (2019) even stated that the initial stages of teaching students writing through a dialogic approach are powerful to develop their ideas and to establish their opinion and voice regarding an assigned topic.

Moreover, a certain dimension of teacherstudent interaction within the framework of dialogic teaching approach was elaborated by some scholars and further became the baseline principles for conducting this study. For example, Alexander (2008) explained five principles of dialogic teaching approach which depict the nature of a dialogic learning environment as opposed to the transmissivity of traditional learning. These principles of dialogic teaching ensure that teaching should be (a) collective in which teachers and students address learning tasks or work together; (b) reciprocal so that teachers and students attend to each other, share ideas, and consider alternative perspectives; (c) supportive where students assist each other's learning; (d) cumulative in that teachers and students build on each other's ideas to construct coherent investigations; and (e) purposeful with teachers ensuring that discussions are designed to achieve specific educational goals. Given the nature of those principles, Wingate (2019) further proposed several strategies in dialogic teaching interaction. First, teachers should position students as knowledgeable conversation partners in order to develop their confidence in expressing their ideas as well as critical thinking. Secondly, they should expand the conversation by acknowledging the students' contribution and their perspectives. Lastly, the teacher should provide high-level evaluations of the student contributions by acknowledging their importance, and enhancing their confidence by reassuring moves and praise.

Engagement theory and the construction of voice Systemic Functional Linguistics (SFL) offered engagement resources to provide a theoretical framework for examining the play of various voices around opinions in discourse (Martin \& White, 2005). This theory facilitates the categories for understanding the way to achieve meanings through contextually appropriate linguistic resources (Zhang,
2018), thus enabling the researchers to analyze the emergence of students' voices in their argumentative texts.

There are two discursive features of the engagement system (Martin \& White, 2005) which are called Monoglossia and Heteroglossia. Monoglossia is a language source that is less dialogic or barely effort to engage and negotiate the readers to the writers' viewpoint. On the other hand, Heteroglossia is a variety of linguistic resources which is used to engage the readers to open up or close down options for dialogistic locution. Within Hetereglossic resource, there are also some subcategories, namely contraction (i.e., Disclaim: deny, Disclaim: counter. Proclaim: concur, Proclaim: pronounce, Proclaim: endorse, and Proclaim: justify) and Expansion (i.e., Attribute and entertain). Those Heteroglossic features are portrayed Figure 1.

\section{METHOD}

A qualitative method, specifically case study research, is considered as the most appropriate method for this study, since it focuses on discovery, insight, and understanding of people's practice, and indeed, seeing the dynamic of the practice from the perspectives of those being studied (Merriam, 2009). To gain a clear and holistic picture of the context being studied, multiple data sources were employed;

(1) direct observations (an onsite pre- observations), (2) records of dialogic interaction in MIM, (3) students' argumentative texts, and (4) interviews. Those data sources were utilized to answer the following research questions:

1. How does the process of teacher- student dialogic interaction in MIM contribute to the students' establishment of voice in their argumentative text?

2. How is voice reflected in the students' texts?

\section{Context and participants of the research}

This study involved 37 first-year students of a private university located in one mid-size city in West Java, Indonesia. They are all majoring in English Education Study Program, who were taking a course in Writing for General Communication. Due to Covid-19 Pandemic, the course was delivered fully online.

However, prior to the institutional policy to temporarily shut down the face-to-face instructions, the researchers conducted an on-site direct observation, within which, they asked the students to compose an argumentative text under a topic "Social Media Bring More Harm than Good". After the students collected their writing, the researchers then analyzed their texts. To gain more detail, in- depth, and richness of the data being analyzed, after analyzing the students' argumentative writing, the researchers selected only five students to participate 
further in the project (see Table 1, names on the table are anonymous). The intention to choose them as participants were based on the consideration from the course instructor and the appearance of voice in their writing.

\section{Figure 1}

Subcategories of Heteroglossic resources (Martin \& White, 2005)

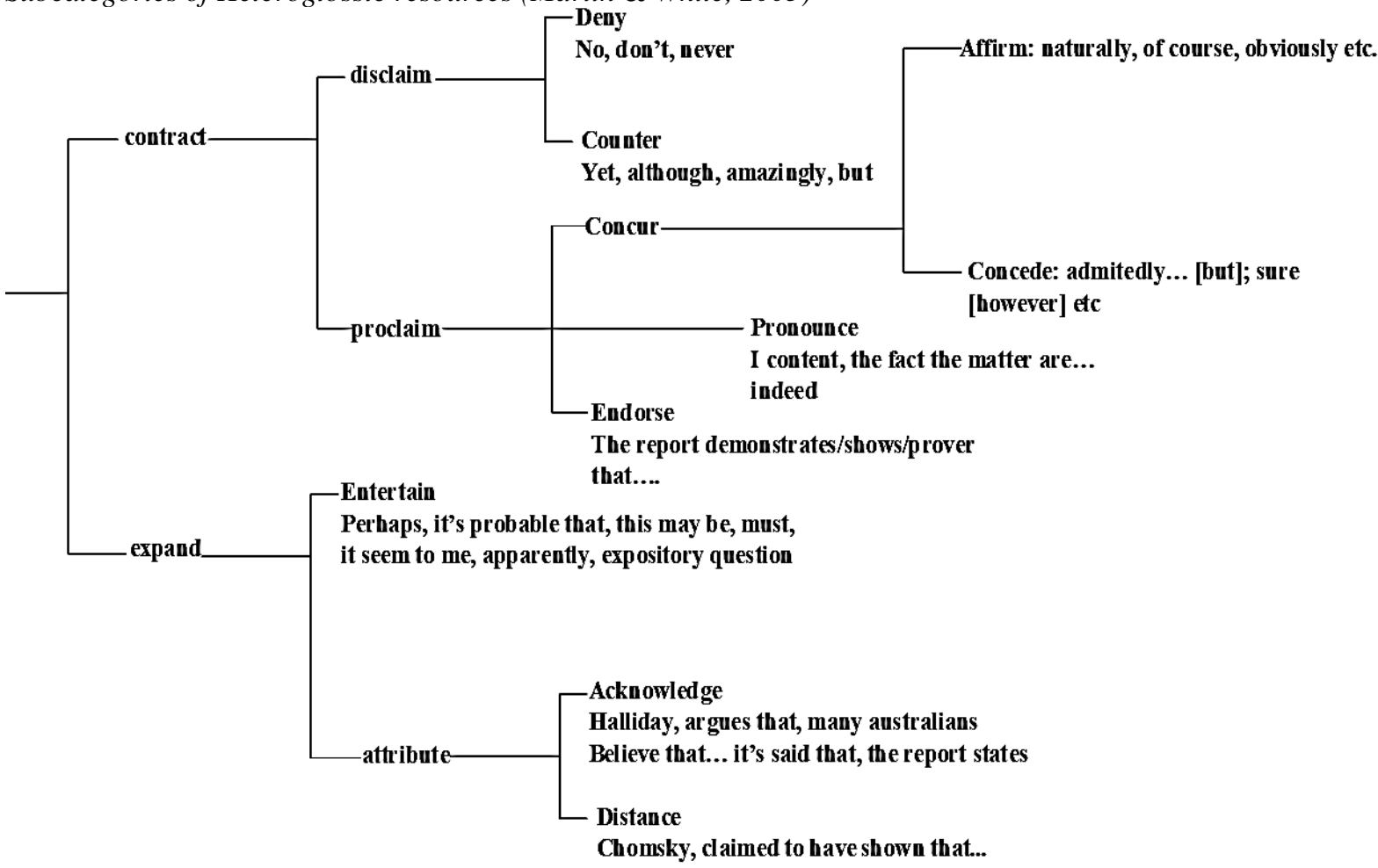

Table 1

Background Information of the Participants

\begin{tabular}{lccc}
\hline $\begin{array}{l}\text { Name } \\
\text { (pseudonym) }\end{array}$ & Age & Gender & $\begin{array}{c}\text { Temporary } \\
\text { GPA }\end{array}$ \\
\hline Angga & 20 & Male & 3.64 \\
Rima & 19 & Female & 3.91 \\
Dira & 19 & Female & 3.75 \\
Kanaya & 19 & Female & 3.72 \\
Sheila & 19 & Female & 3.44 \\
\hline
\end{tabular}

\section{Pedagogical procedure}

As the dominant messaging application that is commonly used in educational contexts (Hamad, 2017), WhatsApp was utilized as the representation of MIM in this study. The instructor created a WhatsApp group, inviting the five participants to join. The interaction in the WhatsApp group consisted of formal and informal interaction. Formal interaction was when the instructor delivering the course material, which was held twice a week over a period of four weeks. As can be seen in Table 2, there were 7 online meeting sessions, normally consisting of 1.5 hours, in which the teacher and students discussed the course material related to voice in argumentative writing. In the time which has been decided by all the participants, the instructor firstly sent the file which contained learning materials, a sample essay, and the practice of the material. Further, she invited the participants to virtually discuss the material she has sent. Out of the formal meeting sessions which had confirmed time and date, the instructor allowed the participants to have informal interaction; for example, if they wanted to ask questions, share knowledge, or even greet each other. The examples of formal discussion sessions in the WhatsApp group could be seen in the appendix.

Furthermore, adopting pedagogical intervention from Jou's (2019) study, which explicitly used engagement pedagogical scheme to scaffold students' awareness of voice, this study divided the course materials into three episodes; (1) online meetings 1-2 that focus on the structure of argumentation; (2) online meetings 3-4 which concern on understanding neutral and evaluative voice and how to use it in establishing thesis or claim; (3) online meetings 5-7 which concern on the linguistic realization of voice in argumentative writing.

\section{Data analysis}

The collected data from observations, WhatsApp conversations, and interviews were firstly transcribed and then translated into English. The data were further analyzed by using inductive analysis method which was proposed by Hatch (2002). Inductive data analysis is "a search for patterns of meaning in data so that general statements about phenomena under investigation can be made" (Hatch, 2002, p. 161). In 
relation to the first research question, the analysis process focuses on finding the features of teacherstudents' dialogic interaction and the contribution of such interaction to the students' awareness of voice. Moreover, to answer the second research question, Engagement Theory was utilized as an analytical framework to analyze the students' voice construction in their argumentative texts. The students' texts were firstly parsed into clauses and all of the clauses were coded based on the subcategories of the Engagement framework; Monogloss,
Disclaim: deny, Disclaim: counter, Proclaim: pronounce, Proclaim: concur, Proclaim: endorse, Proclaim: justify, Entertain and Attribute. In the process of coding the texts, this study employed UAM Corpus Tool (O'Donnell, 2008) for the purpose of creating text corpora. This corpus device is a software application which is considered appropriate for categorizing the overlapping types of Engagement resources because it allows segments to be annotated with more than one feature of Engagement.

Table 2

Online Session Topics and Assignments

\begin{tabular}{cll}
\hline $\begin{array}{c}\text { Online discussion } \\
\text { sessions }\end{array}$ & \multicolumn{1}{c}{ Topic } & Assignments \\
\hline Session 1-2 & Structure of argumentative text \\
Session 3-4 & Establishing claim/thesis through understanding & Draft 1 (I) \\
& $\begin{array}{l}\text { Neutral and evaluative voice } \\
\text { Session 5-7 }\end{array}$ & Draft 2 (II) \\
& Contractive and Expansive voice & Final draft (III) \\
\hline
\end{tabular}

\section{FINDINGS AND DISCUSSIONS}

The process of dialogical interaction in MIM as a mean of fostering students in constructing voice Online discussion 1-2: Engaging students in dialogic conversations about the argumentative structure

Referring to the baseline data from pre-observation, the five participants still encountered problems in composing structured argumentative writing. This could be problematic because inviting students to discuss voice while neglecting the concept of how voice should be inserted in the right organization of argumentation would probably lead to inconclusive results. Thus, the focus of the first episode of online discussion was on the pattern of argumentative text. It was specifically concerned with providing background, thesis, logical sequence, supporting arguments, and reinforcement of thesis.

In initiating the discussion, the teacher firstly sent the feedback of their first draft of argumentative writing as well as the file of course material to the WhatsApp group. She asked the students to read and discuss the feedback and further invited them to analyze the sample essay on that file to compare their first draft with the sample essay. The dialogic interaction among teacher and students could be represented on the vignette (a),

[1] [16:09] Instructor : : Rima, how do you know what the writer [was] trying to say? Which part of the intro that explains the detail of the upcoming arguments?

[2] [16:12] Instructor : Dira, can you help?

[3] [16:14] Dira $\quad$ : Because the writer will further explain the points of her arguments

[4] [16:15] Rima : Because at the last sentence of introduction she said will explain

[5] [16:16] Instructor : : Yes, that's it. In the last sentence of introduction, commonly the writers mention the arguments they wanted to explain.

As seen in the vignette (a), the instructor involved the students in the process of knowledge construction by initiating several questions that triggered the students' understanding of the material (line 1). She also invited the other student to share her understanding as the way to include the role of peers in dialogic activities (line 2). This somehow relates with the function of dialogic interaction, where the tutors must consider the students' knowledge as a vital resource to empower them to improve their writing (Merkel, 2019; Wingate, 2019). In turn, such strategies could further influence the awareness of students of the content being discussed (e.g., lines 3 and 4).

In the end, the online dialogic interaction has been positively perceived by the students as meaningful activities to acquire knowledge of how to write an organized argumentation, as confirmed by Dira's statement from the interview in excerpt (a),

"The discussion helped me a lot, especially in realizing that there are some patterns of argumentation which make our argumentative text more convincing. I did not know it before, until I participated in the online discussion."

Online discussion 3-4: Fostering the students' awareness in expressing their claim by discussing neutral and evaluative voice

In this phase, the instructor invited students to discuss neutral and evaluative voice as well as their function in construing claims and argumentation. She provided some sentences to be analyzed and asked students to have a dialogic conversation on this particular topic. The five sentences they discussed were: 
(1) Almost 8.6 percent of the U.S homeless population is comprised of veterans.

(2) Online discussion may possibly foster the learners' writing development.

(3) This study is conducted in a private university.

(4) The government should be responsible for the high toll of Covid-19 victims.

(5) Many Indonesian people are bilingual or even multilingual.

Following the activities, the teacher asked the students to analyze the appearance of neutral and evaluative voice in the sample essays and compare it to their first writing draft. The dialogic interaction which occurred in this session could be seen from the vignette (b).

[1] [16:19] Instructor : How about number 2?

[2] [16:19] Sheila

: Wait, Miss. Sorry.

[3] [16:20] Sheila

: Evaluative, miss??

[4] [16:20] Instructor : Why do you think so?

[5] [16:22] Sheila: Because it shows the writer's judgment.

[6] [16:22] Instructor : Okay, which words do you think could be the sign of evaluative?

[7] [16:22] Instructor : Dira, you may help.

[8] [16:23] Dira : Same with Sheila miss. I think it is evaluative because there is word may possibly.

[9] [16:24] Instructor : Sheila do you agree?

[10] [16:24] Sheila : : Yes, for example in point 2 , miss.

As shown in the vignette, the instructor did not only challenge the analytical thinking of the students, but she also created conditions that would encourage the students to engage in dialogic exchanges. For instance, by asking for Dira's opinion (line 7), she encouraged the students to listen to each other, share ideas, and consider alternative perspectives (Alexander, 2008; Gillies, 2015). It is relatable with the statement from Rima, which stated that she was feeling comfortable with the atmosphere of the discussion.

Excerpt (b),

"What I like from our virtual discussion [was] the atmosphere we establish. You (instructor) always responded to my questions, and I was never afraid of asking any question or delivering comments. When I argue or comment something, the other students also respected my comment, and we share our opinion [with] each other"

The statements asserted that the process of WhatsApp discussion occurred in the situation that allows students to be open with each other, respect each other, and utilize the others' opinions as resources to build dialogic interaction. This suitable condition is so helpful for students in constructing knowledge because they feel that their voice is heard and not as 'threats' for the others (Ludvigsen et al., 2019). Thereby, as this session ended, all students were able to differentiate between evaluative and neutral voice and how to insert them effectively in argumentative writing.

Online discussion 5-7: Exposing the students to the linguistic realization of voice

Within this phase, the focus of online discussion was to expose the students to the linguistic realization of voice. The teacher explicitly mentioned the type of Engagement resource and introduced the function of its features. Particularly, she exposed the students to the language representation of Engagement strategies that could be used to evaluate and comment on information, to provide supporting evidence, to create interpretations of the external information, to know the resources of modality used to set up or argue claims and how to align reader to the position advanced in the thesis (Miller et al., 2014). The feature of dialogic interaction could be identified from the vignette (c),

[1] [17:07] Instructor : : Alright, well please take a look at your first draft and analyze what language resources implied your voice?

[2] [17:13] Dira : Lots of self-mention miss, but there is no references.

[3] [17:17] Rima : There are reasoning, countering, modality. But same with Dira, there is no reference.

[4] [17:18] Kanaya : Self-mention, and there is no reference.

[5] [17:18] Instructor : How about an endorsement, countering, and emphasizing?

[6] [17:18] Rima : No endorsement Ms, hehe.

[7] [17:20] Kanaya : : Not yet, miss.

[8] [17:21] Instructor : Okay. Now, please compare with your second writing, is there any difference in terms of voice?

[9][17:24] Kanaya $\quad:$ Yes, there is, miss. In the second draft I have provided references, emphasizing words like certainly and so on. But there is no endorsement yet, hehe.

[10][17:24] Instructor : Very good. How about the others?

[11][17:24] Rima : Yes miss, there is a reference in my second draft.

[12][17:25] Dira : There are some references, miss.

It was apparent from vignette (c), that the teacher asked the students to analyze the establishment of language resources that indicate voice in their own writing drafts (line 1). She further challenged the students to compare the voice 
resources in the first and the second draft in order to make them aware of their voice development (line 5). As shown, the students have been aware of the missing voice in their text such as the need for references as well as endorsements (lines 9, 11, and 12). These activities are in line with the soul of dialogic interaction in which the teacher scaffolds the students' knowledge through connecting previous information to what they are currently learning. She also encouraged students to explicate their reasoning and thinking by listening attentively to students' answer then probed and challenged their thinking (Gillies, 2015).

From the vignette, it was also clear that through the dialogic interaction, the students show their understanding of the appearance of voice in their writing such as the emergence of affirmation words and external sources. This could be the sign that throughout the process of WhatsApp discussion, students have gained awareness of the need for voice construction in argumentative writing. Therefore, to gain a more holistic feature on the students' voice construction in their writing, the further section of the findings would particularly concern on the reflection of their voice development which was mediated by this WhatsApp dialogic interaction.

\section{Students' voice development in argumentative writing \\ General pattern of Engagement}

In this section, the elaboration of the students' establishment of voice would focus on the emergence of two main discursive features of Engagement, i.e., Monoglossia and Heteroglossia on their three drafts of argumentative writing.

Table 3 shows the percentage of Monoglossia and Heteroglossia in the three writing tasks of the five participants. It reveals that the participants had employed more Heteroglossic move since their first draft of argumentative writing. Yet, the striking difference among the five participants is in terms of the development of both two resources. Sheila and Kanaya appeared to reduce the use of Monoglossic move from their first to their final writing draft. Meanwhile, Angga and Dira showed inconsistency in using Monoglossic voice in their three writing drafts since there are fluctuating percentages of monoglossic move in the first, second, and final revisions. In contrast, there is a slight increase in the frequency of Monogloss in Rima's first draft toward the final draft.

Table 3

Percentage of Monogloss and Heterogloss Feature in Students' Drafts

\begin{tabular}{lrrcccc}
\hline & \multicolumn{3}{c}{ MONOGLOSS } & \multicolumn{3}{c}{ HETEROGLOSS } \\
\cline { 2 - 6 } & I & II & III & I & II & III \\
\cline { 2 - 7 } & \multicolumn{5}{c}{$f($ frequency) $/ 1000$ words (\%) } \\
\hline Angga & 24.00 & 25.00 & 23.53 & 76.00 & 75.00 & 76.47 \\
Rima & 5.56 & 25.00 & 25.86 & 94.44 & 75.00 & 74.14 \\
Dira & 33.33 & 35.48 & 22.22 & 66.67 & 64.52 & 75.00 \\
Kanaya & 33.33 & 25.64 & 16.33 & 66.67 & 74.36 & 83.67 \\
Sheila & 46.43 & 16.67 & 23.81 & 53.57 & 83.33 & 76.19 \\
\hline
\end{tabular}

Minimizing the emergence of Monoglossia and increasing the occurrence of Heteroglossia somehow portrays the writers' effort to use dialogically engaged wordings rather than merely providing bare assertions (Lancaster, 2014). However, comparing Monoglossic and Heteroglossic move is profoundly not adequate to depict the entire voice development in the students' writing. Thus, the detailed analysis of each feature of Heteroglossic move is necessary to gain a more conclusive feature of students' voice construction and development.

\section{Heteroglossic resources in students' draft I}

Table 4 shows the first draft of students' argumentative writing. Some of the students shared similarities in which they tried to establish their stance and justification in their writing through the appearance of Proclaim: pronounce and justify. They also attempted to bring alternative perspectives by the use of Disclaim: counter and deny. However, their judgments or stances lacked confidence or commitment to truth-value since the percentage of
Entertain move is relatively high compared to the other features of Engagement.

Additionally, there is also no attributive move in all of the students' first drafts, indicating that they did not involve external sources or references to support their personal argument. Most of them also did not incorporate Proclaim: concur and proclaim: Endorse as the language resources to affirm the readers on their argumentation. These make their first draft writing only self-argumentation, which leads to less dialogic and persuasive argumentative text, such as what occurred in Angga's first draft.

Excerpt (c)

Social media is just media, and it is about how we use it if we use it for good things it will be good too but if we use it for bad things it will be bad too. The key is education its our job to educate everybody to use social media wisely. Imagine if we lose our media to express everything it will be worse. 
Table 4

Percentage of Heteroglossic Features in Students' Draft 1

\begin{tabular}{lrrrrrrrrr}
\hline & Deny & Counter & Concur & Pronounce & Endorse & Justify & Entertain & Attribute & $\begin{array}{c}\text { Total T-units } \\
\text { (N) }\end{array}$ \\
\hline Angga & 12 & 4 & - & 20 & - & 4 & 36 & - & 25 \\
Rima & 16.67 & 11.11 & 5.56 & 16.67 & - & 5.56 & 38.85 & - & 18 \\
Dira & 8.33 & - & - & - & - & - & 58.36 & - & 12 \\
Kanaya & 6.67 & - & 6.67 & 20 & - & 13.33 & 20 & - & 15 \\
Sheila & - & 7.14 & 14.29 & - & - & 7.14 & 25 & - & 28 \\
\hline
\end{tabular}

Angga used abundant numbers of Entertain moves to propose his argument that social media is not harmful to society. He integrated conditional sentence (if, imagine) and modal verbs (will be) to establish a dialogic viewpoint through open up the dialogic space to alternatives. However, presenting an authorial voice without interactively engaging with the voice of others will possibly distract the readers whose opinions are more authoritative than their own (Lancaster, 2014). Thus, it seems necessary for students to be able to construe their voice by recognizing or mentioning external resources while still committing to their own argumentations (Latipah \& Gunawan, 2020). The intention is to make them aware that Entertain move with persuaded judgments should be based on empirical research and analytic models in order to construct authoritative stances while also conveying evaluative caution (Lancaster, 2014).

\section{Heteroglossic resources in students' draft II}

In the second revision of students' argumentative text, the role of the dialogic interaction on the students' voice construction was clearly visible. From table 5, it could be identified that students involved more various resources of Heteroglossia. Although the percentage of Entertain move is still high, the performance of the other sources is increased. For instance, most of them had tried to employ the Attribute move in their writing which shows that they have attempted to strengthen their argument through providing factual evidence that could function as a justification of their arguments. They also incorporated Proclaim and Disclaim features such as Proclaim: concur to emphasize their justification, Proclaim: pronounce to convey their personal stance, Proclaim: justify to give reasoning of their arguments, and Disclaim: deny and counter to address other possible viewpoints.

Table 5

Percentage of Heteroglossic Features in Students' Draft 2

\begin{tabular}{lccccccccc}
\hline & Deny & Counter & Concur & Pronounce & Endorse & Justify & Entertain & Attribute & $\begin{array}{c}\text { Total T-units } \\
\text { (N) }\end{array}$ \\
\cline { 2 - 8 } & & \multicolumn{7}{c}{ f/1000 } & words $(\%)$ \\
Angga & - & 7.14 & - & 17.86 & - & 3.57 & 42.86 & 3.57 & 28 \\
Rima & 11.54 & 3.85 & 5.77 & 7.69 & 1.92 & 3.85 & 38.46 & 1.92 & 52 \\
Dira & - & 6.45 & 3.23 & 12.90 & - & 6.45 & 25.81 & 9.68 & 31 \\
Kanaya & 5.13 & 7.69 & 7.69 & 5.13 & - & 7.69 & 28.21 & 12.82 & 39 \\
Sheila & 8.33 & - & - & 20.83 & - & 4.17 & 50.00 & - & 24 \\
\hline
\end{tabular}

Unfortunately, their efforts to involve reference to build up their stance were not followed by the evaluative judgment toward the external sources, or they did not link reference with their own perspectives. The appearance of Attribute feature was only for the purpose of citing external information, thereby they create mostly summative texts without evaluating the attributed positions (Jou, 2019). It could be clarified by the data in table 5 , that almost no Proclaim: Endorse emerged in the students' draft II. Taking Kanaya's writing as an example, Attribute move appeared $12.82 \%$ in her text, but zero percentage of Proclaim: Endorse occurred in her text.

Excerpt (d)

Secondly, social media can be used as a buying and selling media that is abused, such as drug trafficking. For example, reported (Attribute) by wartakotalive.com, the ranks of the Narcotics Police Soekarno-Hatta Airport arrested Instagram account owner,
@ dr.bankbong, in Pontianak, West Kalimantan on July 25, 2019. The perpetrators openly offered methamphetamine drugs along with words to lure their customers, because (proclaim justify) social media is considered as a private media that can be accessed by everyone and certainly (proclaim: concur) gives criminals the freedom to do bad things.

Through providing an external voice, Kanaya gave the example of how social media could be misused by criminals. She took the information from a certain website and put it as the attribute to provide dialogic expansion of her voice. Yet, until the end of the paragraph, there was no Proclaim: Endorse to clarify that the source text is correct, valid, undeniable, or otherwise, maximally warrantable (Martin \& White, 2005). She only provided justification of their stance through Proclaim: Justify and Proclaim: Concur without trying to offer an 
interpretation of the source text that supports her assertion (Miller et al., 2014). The emergence of Proclaim: Endorse is important in argumentative writing since this pattern allowed students "to construe a Heteroglossic backdrop of potential alternative viewpoints for the proposition, incorporate information from source texts, then build an argument based on their own interpretation of that information (Martin \& White, 2005, p.127).

\section{Heteroglossic resources in students' draft III}

Table 6 shows the appearance of a more diversified Heteroglossic feature in the students' final text. Almost all of them have been able to use various resources of Engagement including the Endorsement feature associated with the Attribute move. Interestingly, the appearance of Entertain feature was also reduced compared to their first and second draft. This impressive progress could be an evidence that the process of online dialogic interaction contributes positively toward the students' voice construction

Table 6

Percentage of Heteroglossic Features in Students' Draft 3

\begin{tabular}{|c|c|c|c|c|c|c|c|c|c|}
\hline & Deny & Counter & Concur & Pronounce & Endorse & Justify & Entertain & Attribute & Total T-units \\
\hline & \multicolumn{8}{|c|}{$f / 1000$ words $(\%)$} & $(\mathrm{N})$ \\
\hline Angga & - & 13.73 & - & 15.69 & 3.92 & 3.92 & 31.37 & 7.88 & 51 \\
\hline Rima & 8.62 & 5.17 & 8.62 & 10.34 & 1.72 & 1.72 & 31.03 & 8.62 & 58 \\
\hline Dira & - & 5.56 & 2.78 & 16.64 & 5.56 & 2.78 & 33.33 & 8.33 & 36 \\
\hline Kanaya & 4.08 & 4.08 & 16.33 & 10.20 & 4.08 & - & 24.49 & 20.41 & 49 \\
\hline Sheila & & 2.38 & - & 11.90 & - & 2.28 & 57.14 & 2.38 & 42 \\
\hline
\end{tabular}

However, not all of the students showed an advancement in progress. For example, until the final draft, Sheila tended to employ more Entertain moves $(57.14 \%)$ in comparison with her first $(25 \%)$ and second drafts $(50 \%)$. She also provided fewer attribute moves $(2.38 \%)$ and even no Endorsement and Concur moves $(0 \%)$ in her final draft. This fact indicated that, in Sheila's case, establishing dialogic discussion about how to construe voice in argumentative writing was considered an inappropriate method for enabling her to gain a greater awareness of voice. This was clarified by Sheila's statement in the interview, that she had great problems in engaging and understanding the topic of discussion as well as establishing voice in argumentative writing because her English vocabularies and grammatical knowledge were very limited.

Excerpt (e)

"I am really aware that the discussion process is heavily meaningful to improve my writing skill, but then, it was so hard for me to understand the material and respond to the discussion. As a beginner learner, I have limited English vocabulary and grammatical knowledge. I did face difficulties to write as you expected because it liked bringing me to the beyond level of my capacity.

This finding is aligned with the statement from Jou (2019) who said that students' lexical knowledge manifested as a factor affecting their understanding of why some texts projected an expansive voice while others a contractive one. Additionally, Wingate (2019) argued that the goals of dialogic interaction would be difficult to achieve when students' language proficiency and quality of draft were low. Thus, for a certain case, such as Sheila, language- focused sequences that aimed at improving the accuracy of texts were more appropriate to be given, involving considerable amount of monologic instruction.

\section{CONCLUSIONS}

This study aimed to answer the questions of how the practice of dialogic interaction through instant messaging plays a role to support students' voice construction in argumentative writing as well as the degree of students' voice in their writing. Three episodes of online discussion sessions were presented along with the analysis of the three drafts of students' argumentative text. The findings revealed that within the practice of dialogic interaction, the teacher tended to apply the characteristic of dialogic interaction, such as ensuring the convenient atmosphere for students to freely express and share ideas and consider alternative perspectives (Alexander, 2008; Gillies, 2015), positioning the student as a vital resource of knowledge construction through acknowledging their importance (Wingate, 2019) and allowing them to discover ideas by challenging their reasoning and thinking. However, the findings of the data analysis show a varied result of students' uptake in establishing voice. Four students claimed that the process of dialogic interaction was a helpful and meaningful activity for them to know how to apply voice effectively in argumentative text. Those were further clarified by their progressive development of voice construction in the first to their final drafts of argumentative writing. On the contrary, although certain improvements were still able to be identified, the one remaining student did not show promising progress due to her limitation in English proficiency.

Furthermore, several limitations could be acknowledged in this study. First, although virtual 
interaction through instant messaging was considered meaningful to stimulate the students' awareness of repertoires in argumentative writing, in the process of online discussion, it was rather hard for the teacher to control the presence of each student. Ensuring students' engagement is always being a huge obstacle in virtual discussions because the teacher was unable to maintain the students' commitment to respond to the discussion since they were physically separated. Secondly, the interaction in instant messaging only occurred in textual mode (chatting) and audio record (voice note), thus non- verbal expressions such as face mimic or body gesture could not be involved as supplemented data in analyzing the move of dialogic interaction. Therefore, it is recommended for future research to optimize the synchronous feature of MIM such as video conferencing, to gain more holistic and comprehensive data of the teacher-students' virtual interaction.

\section{ACKNOWLEDGEMENT}

The authors of this paper would like to express profound gratitude to Indonesia Endowment Fund for Education (LPDP) for providing financial support to accomplish this research.

\section{REFERENCES}

Alebaikana, R., \& Troudia, S. (2010). Online discussion in blended courses at Saudi Universities. Proceedia Social and Behavioral Sciences, 2(2), 507-514. https://doi.org/10.1016/j.sbspro.2010.03.05

Alexander, R. J. (2008). Towards dialogic teaching: Rethinking classroom talk (4th ed.). Dialogos.

Andujar, A. (2016). Benefits of mobile instant messaging to develop ESL writing. System, 62, 63-76. https://doi.org/10.1016/j.system.2016.07.004

Andújar-vaca, A., \& Cruz-Martínez, M. (2017). Mobile Instant Messaging: Whatsapp and its potential to develop oral skills. Media Education Research Journal, 25(50), 43-52. https://doi.org/10.3916/C50-2017-04

Awada, G. (2016). Effect of Whatsapp on critique writing proficiency and perceptions toward learning. Cogent Education, 3(1), 1-25. http://dx.doi.org/10.1080/2331186X.2016.126 4173

Azevedo, B. F. T., Behar, P. A., \& Reatagui, E. B. (2011). Qualitative analysis of discussion forums. International Journal of Computer Information Systems and Industrial Management Applications, 3, 671-678.

Bakhtin, M. M. (1981). The dialogic imagination: Four essays. University of Texas Press.

Cheung, K. Y. F., Elander, J., Stupple, E. J. N., \& Flay, M. (2018). Academics' understandings of the authorial academic writer: A qualitative analysis of authorial identity. Studies in Higher
Education, 43(8), 1-16. https://doi.org/10.1080/03075079.2016.126438 2

Dressen-Hammouda, D. (2014). Measuring the voice of disciplinarity in scientific writing: A longitudinal exploration of experienced writers in Geology. English for Specific Purposes, 34, 14-25. https://dx.doi.org/10.1016/j.esp.2013.10.001

Gillies, R. M. (2015). Dialogic interactions in the cooperative classroom International Journal of Educational Research, 76, 178-189. http://dx.doi.org/10.1016/j.ijer.2015.02.009

Guinda, C. S., \& Hyland, K. (2012). Stance and voice in written academic genres. Palgrave Macmillan.

Hamad, M. M. (2017). Using WhatsApp to enhance students' learning of English language "Experience to Share." Higher Education Studies, 7(4), 74-87. http://doi.org/10.5539/hes.v7n4p74

Hammond, J. (2016). Dialogic space: Intersections between dialogic teaching and systemic functional linguistics, Research Papers in Education, 31(1), 5-22. http://dx.doi.org/10.1080/02671522.2016.1106 693

Hatch, J. A. (2002). Doing qualitative research in education setting. State University of New York Press.

Hewings, A. 2012. Stance and voice in academic discourse across channels. In K. Hyland \& C. S. Guinda (Eds.), Stance and voice in written academic genres (pp. 187-201). Palgrave Macmillan.

Hyland, K. (2012). Undergraduate understandings: Stance and voice in final year reports. In K. Hyland \& C. S. Guinda (Eds.), Stance and voice in written academic genres (pp. 134150). Palgrave Macmillan.

Jesson, R., \& Rosedale, N. (2016). How teachers might open dialogic spaces in writing instruction. International Journal of Educational Research, 80, 164-176. http://dx.doi.org/10.1016/j.ijer.2016.08.003

Jou, Y. (2019). Scaffolding L2 writers' metacognitive awareness of voice in article reviews: A case study of SFL-based pedagogy. Journal of English for Academic Purposes, 41, 1-16. https://doi.org/10.1016/j.jeap.2019.100770

Lancaster, Z. (2014). Exploring valued patterns of stance in upper-level student writing in the disciplines. Written Communication, 31(1), 27-57. https://doi.org/10.1177/0741088313515170

Latipah, Y. \& Gunawan, W. (2020). Undergraduate students' voice construction in Padlet online discussion. Proceedings of International Conference of Information and Education 
Technology, 122-126.

https://doi.org/10.1145/3395245.3396445

Lee, J. J., \& Deakin, L. (2016). Interactions in L1 and L2 undergraduate student writing: interactional metadiscourse in successful and less-successful argumentative essays. Journal of Second Language Writing, 33, 21-34. http://dx.doi.org/10.1016/j.jslw.2016.06.004

Ludvigsen, K., Ness, I. J., \& Timmis, S. (2019). Writing on the wall: How the use of technology can open dialogical spaces in lectures. Thinking Skills and Creativity, 34, 118. https://doi.org/10.1016/j.tsc.2019.02.007

Martin, J. R., \& White, P. R. R. (2005). The language of evaluation: Appraisal in English. Palgrave.

Merkel, W. (2019). "What I Mean Is...”: The role of dialogic interactions in developing a statement of teaching philosophy. Journal of Second Language Writing, 48, 100702. https://doi.org/10.1016/j.jslw.2019.100702

Merriam, S. B. (2009). Qualitative research: A guide to design and implementation. San John Wiley \& Sons, Inc.

Miller, S., Mitchell, T. D., \& Pessoa, B. (2014). Valued voices: Students' use of Engagement in argumentative history writing. Linguistics and Education, 28, 107-120. http://dx.doi.org/10.1016/j.linged.2014.10.002

Minalla, A. A. (2018). The effect of WhatsApp chat group in enhancing EFL learners' verbal interaction outside classroom contexts. English Language Teaching, 11(3), 1-7. http://doi.org/10.5539/elt.v11n3p1

O'Donnell, M. (2008). The UAM corpus tool: Software for corpus annotation and exploration. Proceedings of the XXVI Congreso de AESLA, 1433-1447.

Pessoa, S., Mitchell, T. D., \& Reilly, B. (2019). Scaffolding the writing of argumentative essays in history: A functional approach. The History Teacher, 52(3), 411-440.

Pimmer, C., Mateescu, M., \& Grohbiel, U. (2016). Mobile and ubiquitous learning in higher education settings. A systematic review of empirical studies. Computers in Human Behavior, 63, 490-501. http://dx.doi.org/10.1016/j.chb.2016.05.057

Reina, L., \& Clark, S. K. (2019). Teaching students to write opinion pieces using a dialogic approach. The Reading Teacher, 73(3), 357361. https://doi.org/10.1002/trtr.1848

Sivabalan, \& Ali, Z. (2019). A systematic review on mobile instant messaging as a collaborative tool for language learning. International Journal of Language Education and Applied Linguistics, 9(1), 99-109.

Skidmore, D., \& Murakami, K. (2016). Dialogic pedagogy: The importance of dialogue in teaching and learning. CPI Books Group Ltd.
So, S. (2016). Mobile instant messaging support for teaching and learning in higher education. Internet and Higher Education, 31, 32-42. https://doi.org/10.1016/j.iheduc.2 016.06.001

Ta'amneh, A. (2017). The effect of using "WhatsApp Messenger" in learning English language among university students. International Journal of Humanities and Applied Social Science, 2(2), 15-22. https://doi.org/10.5296/ire.v5i1.10801

Tan, K. (2016). Using online discussion forums to support learning of paraphrasing. British Journal of Educational Technology, 48(6), 1239-1249. https://doi.org/10.1111/bjet.12491

Tang, Y., \& Hew, K. F. (2017). Is mobile instant messaging (MIM) useful in education? Examining its technological, pedagogical, and social affordances. Educational Research Review, 21, 85-104. https://doi.org/10.1016/j.edurev.2017.05.001

Teo, P. (2016). Exploring the dialogic space in teaching: A study of teacher talk in the preuniversity classroom in Singapore. Teaching and Teacher Education, 56, 47-60. https://doi.org/10.1016/j.tate.2016.01.019

van Eemeren, F. H. (2018). Argumentation theory: A pragma-dialectical perspective. Springer.

Van Der Heide, J., Juzwik, M., \& Dunn, M. (2016) Teaching and learning argumentation in English: A dialogic approach. Theory into Practice, 55(4), 287-293. https://10.1080/00405841.2016.1208069

Winet, D. (2016). Mobile instant messaging in the ESL writing class. The Electronic Journal for English as Second Language, 20(3), 1-6.

Wingate, U. (2019). 'Can you talk me through your argument'? Features of dialogic interaction in academic writing tutorials. Journal of English for Academic Purposes, 38, 25-35. https://doi.org/10.1016/j.jeap.2019.01.001

Woods, K., \& Bliss, K. (2016) Facilitating successful online discussions. The Journal of Effective Teaching, 16(2), 76-92.

Yoon, H. (2017). Writing Textual voice elements and voice strength in EFL argumentative writing. Assessing Writing, 32, 72-84. https://doi.org/10.1016/j.asw.2017.02.002

Zacharias, N. T. (2018). Voice construction and development of a multilingual student writer: A Bakhtinian perspective. RELC Journal, 51(2), 268-279. https://doi.org/10.1177/0033688218810548

Zhang, F., \& Zhan, J. (2019). Understanding voice in Chinese students' English writing. Journal of English for Academic Purposes, 45, 100844. https://doi.org/10.1016/j.jeap. 2020.100844

Zhang, X. (2018). Supporting EFL Learners' reflective practices through systemic functional linguistic praxis: A Longitudinal case study. Educational Sciences: Theory \& Practice, 18, 
495-513.

http://dx.doi.org/10.12738/estp.2018.2.0022

Zhao, C. G. (2019). Writer background and voice construction in L2 writing. Journal of English for Academic Purposes, 37, 117-126. https://10.1016/j.jeap.2018.11.004
Zhao, C. G., \& Liosa, L. (2008). Voice in highstakes L1 academic writing assessment: Implications for L2 writing instruction. Assessing Writing, 13, 153-170. https://10.1016/j.asw.2008.10.003

\section{APPENDIX}

The examples of online meeting discussion in WhatsApp group

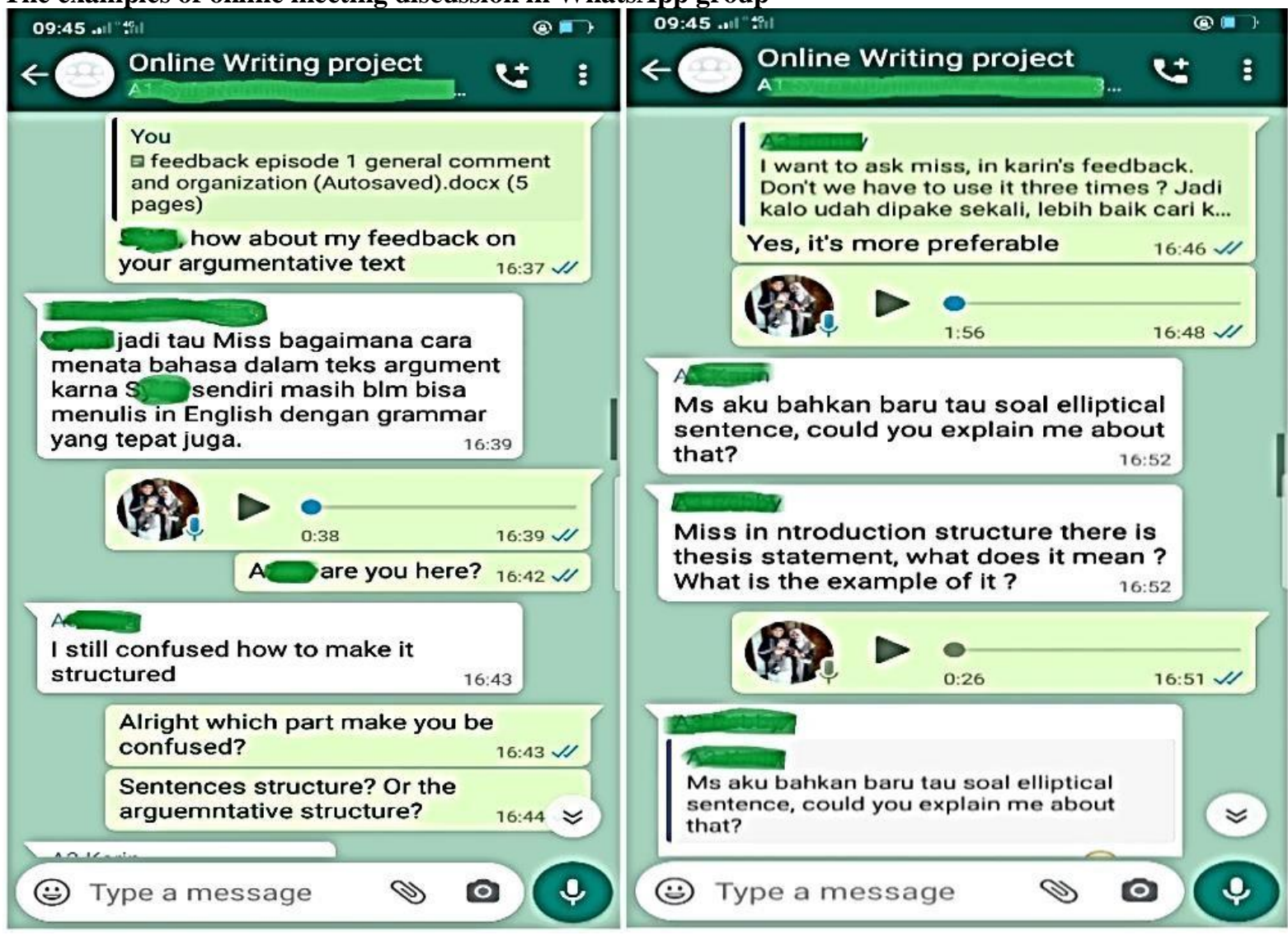

